\section{Substituting Pine Wood for Pine Bark Affects Physical Properties of Nursery Substrates}

\author{
James E. Altland ${ }^{1,3}$ and Charles R. Krause ${ }^{2}$ \\ USDA-ARS, Application Technology Research Unit, Ohio Agricultural \\ Research and Development Center, 1680 Madison Avenue, Wooster, OH \\ 44691
}

Additional index words. moisture characteristic curve, particle size distribution, unavailable water, pine bark

\begin{abstract}
Pine bark (PB) is currently imported from southern U.S. states to nursery growers in the upper midwest and northeast United States. Alternatives to PB that are regionally abundant and sustainable are needed for nursery substrates. The objective of this research was to determine the influence of pine wood $(\mathrm{PW})$, which consisted of chipped and hammermilled pine trees (excluding branches and needles) on substrate physical properties when substituted partially or wholly for PB in substrates typical of Ohio. Four cooperating nursery sites, each with unique substrates comprised primarily of $P B$, were recruited to use $P W$ as a substitute for $0 \%, 50 \%$, or $100 \%$ of the $P B$ fraction in their substrate. All other physical and chemical amendments used traditionally at each site were incorporated. Physical properties including particle size distribution (PSD), air space (AS), container capacity (CC), total porosity (TP), unavailable water (UAW), bulk density $\left(D_{b}\right)$, and moisture characteristic curves (MCC) were determined for each substrate at each cooperator site. Pine wood was generally more coarse than all but one of the PB materials used by the four cooperating sites. Amendment with PW did not have any consistent or predictable effect on $A S, C C, T P$, or $D_{b}$ of the resultant substrates. Pine wood had little identifiable effect on plotted $\mathrm{MCC}$, although it reduced calculated easily available water in one substrate. It was concluded that substitution of $P B$ with $P W$ can result in changes to substrate physical properties that might lead to irrigation management changes, but none of these changes were considered negative or drastic enough to cause physical properties to be outside of acceptable ranges.
\end{abstract}

Pine bark is the primary component in container nursery substrates, comprising $60 \%$ to $80 \%$ by volume of most substrate blends. Pine bark is a commodity used by other industries including fuel generation, fiber ( $\mathrm{Lu}$ et al., 2006), charcoal, landscape mulch, and as a source for extracting biochemicals. Pine bark is primarily generated dustries, in which trees are debarked for the purpose of obtaining clean wood. The price for PB at any given time is dependent on supply/demand dynamics in the forest products industries as well as transportation and processing costs, which are tied directly to fuel costs.

Received for publication 15 May 2012. Accepted for publication 27 July 2012.

Funding for this research was provided by the Floriculture and Nursery Research Initiative.

We thank Richard Posey of Buckeye Resources for securing and processing the pine wood materials in this experiment.

Mention of proprietary products or company is included for the reader's convenience and does not imply any endorsement or preferential treatment by USDA/ARS.

${ }^{1}$ Research Horticulturist.

${ }^{2}$ Research Leader and Plant Pathologist.

${ }^{3}$ To whom reprint requests should be addressed; e-mail James.Altland@ars.usda.gov. as a byproduct in the forest products in-
A compelling body of research has emerged on the use of whole pine trees as an alternative component to replace $\mathrm{PB}$ as the base substrate (Boyer et al., 2008; Fain et al., 2008, Jackson et al., 2010; Wright and Browder, 2005). The nursery and greenhouse industries can bypass the forest products industry by harvesting whole trees using independent contractors, thus avoiding dependency on the economic volatility of the forest products industry. This research is also appealing to northern U.S. states that could use local pine tree stands instead of the current practice of importing PB from wood mills located primarily in southern U.S. states. The goal of this research was to evaluate the horticultural feasibility of using PW to replace all or part of the PB fraction currently used in container nursery production in Ohio. Specifically, the first objective was to determine the influence of substituting $\mathrm{PB}$ at commercial nursery operations with commercially harvested and processed PW on substrate physical properties.

\section{Materials and Methods}

Chipped pine (Pinus taeda) logs, including bark and wood but excluding branches and needles, were secured commercially from southern Ohio in Mar. 2011. Chips were passed through an industrial hammermill twice (Peterson Pacific, Eugene, OR), first through $7.5-\mathrm{cm}$ screens and then through $5.0-\mathrm{cm}$ screens. The resulting material, hereafter referred to as PW, was stored in a large unprotected pile until delivery to four nursery cooperators throughout northern Ohio identified hereafter as Sites 1 through 4. Once delivered, each cooperator was instructed to produce three substrate blends including: 1 ) their standard substrate (Table 1) with PB as the primary component; 2 ) a modified substrate with $50 \%$ of the PB replaced by PW but with all other physical and chemical amendments similar to their standard substrate; and 3 ) a modified substrate with $100 \%$ of the PB replaced with PW but all other amendments similar to the standard substrate. All substrates were mixed at each cooperating nursery site using their standard equipment and mixing procedures. The resulting substrates were piled on concrete slabs until they were filled in pots for crop production. Before filling pots, a subsample of each substrate was collected and stored in plastic tubs in a climate-controlled building until analyses could be completed. In addition to the mixed substrates, a sample of the PB used by each cooperating site was also collected, stored, and analyzed.
Table 1. Description of substrate components and amendments of the standard substrate for each cooperating nursery site.

\begin{tabular}{|c|c|c|c|}
\hline Site & Substrate components & Fertilizers incorporated & Other amendments \\
\hline Site 1 & $100 \%$ pine bark & Harrell's $18-2-5$ at $6.5 \mathrm{~kg} \cdot \mathrm{m}^{-3}$ & AquaGro $2000^{z}$ at $0.6 \mathrm{~kg} \cdot \mathrm{m}^{-3}$ \\
\hline Site 2 & $\begin{array}{l}67 \% \text { pine bark } \\
20 \% \text { sphagnum peat } \\
13 \% \text { MSW compost }\end{array}$ & $\begin{array}{l}\text { Harrell's } 18-4-8 \text { at } 4.7 \mathrm{~kg} \cdot \mathrm{m}^{-3} \\
\text { Harrell's } 14-7-0 \text { premix at } 4.2 \mathrm{~kg} \cdot \mathrm{m}^{-3}\end{array}$ & Bifenthrin $^{y}$ at $3 \mathrm{~kg} \cdot \mathrm{m}^{-3}$ \\
\hline Site 3 & $\begin{array}{l}60 \% \text { pine bark } \\
30 \% \text { sphagnum peat } \\
10 \% \text { sand }\end{array}$ & $\begin{array}{l}\text { Osmocote } 15-9-12 \text { at } 4.7 \mathrm{~kg} \cdot \mathrm{m}^{-3} \\
\text { Dolomitic limestone at } 4.4 \mathrm{~kg} \cdot \mathrm{m}^{-3}\end{array}$ & \\
\hline Site 4 & $\begin{array}{l}65 \% \text { pine bark } \\
21 \% \text { sphagnum peat } \\
7 \% \text { Regrind compost }^{\mathrm{w}} \\
7 \% \text { haydite }^{\mathrm{v}}\end{array}$ & Dolomitic limestone at $5.0 \mathrm{~kg} \cdot \mathrm{m}^{-3}$ & \\
\hline
\end{tabular}

\section{${ }^{2}$ Media surfactant.}

y'Insecticide.

${ }^{\mathrm{x}} \mathrm{MSW}=$ municipal solid waste compost.

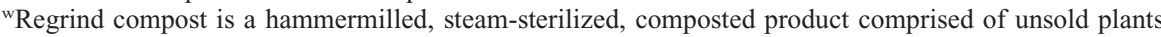
from previous seasons. This material is produced and used exclusively by the cooperating site.

${ }^{v}$ Expanded shale lightweight aggregate. 
Particle size distribution of the PW and differing PB samples from each cooperating site were determined using $\approx 100 \mathrm{~cm}^{3}$ oven dried substrate $\left(60^{\circ} \mathrm{C}\right)$ passed through 19.0 -, 12.5-, 6.30-, 4.0-, 2.8-, 2.0-, 1.4-, 1.0-, 0.71-, $0.50-, 0.35-, 0.25-, 0.18-$, and $0.11-\mathrm{mm}$ sieves. Particles $0.11 \mathrm{~mm}$ or less were collected in a pan. Sieves and pan were shaken for 3 min with a RX-29/30 Ro-Tap ${ }^{\circledR}$ test sieve shaker (278 oscillations/min, 150 taps/min) (W.S. Tyler, Mentor, OH). Three replicate samples for each material were analyzed. Particle size distributions were subjected to multivariate analysis of variance (ANOVA) to determine if distributions differed as a whole and then were analyzed by univariate ANOVA within each sieve size. Means were separated within a sieve size using Fisher's protected least significance difference test, where $\alpha=0.05$. There were three replicate samples analyzed for PW and each PB source.

Substrate physical properties. Mixed substrates were packed in $347-\mathrm{cm}^{3}$ aluminum cores $(7.6 \mathrm{~cm}$ tall $\times 7.6 \mathrm{~cm}$ i.d. $)$ according to methods described by Fonteno and Bilderback (1993). There were three replications for each substrate. Aluminum cores were attached to North Carolina State University Porometers ${ }^{\mathrm{TM}}$ (Horticultural Substrates Laboratory, North Carolina State University, Raleigh, NC) for determination of AS. Cores were weighed, oven-dried for $4 \mathrm{~d}$ at $60{ }^{\circ} \mathrm{C}$, and weighed again to determine CC. Total porosity was calculated as the sum of AS and CC. All physical properties (TP, $\mathrm{AS}, \mathrm{CC})$ were calculated as the algebraic mean of the core. Bulk density was determined using oven-dried $\left(60^{\circ} \mathrm{C}\right)$ substrate in $347-\mathrm{cm}^{3}$ cores. Unavailable water, held in the substrate at $1.5 \mathrm{MPa}$ or greater, was determined with $116-\mathrm{cm}^{3}$ cores $(2.5 \mathrm{~cm}$ tall $\times$ $7.6 \mathrm{~cm}$ i.d.) using a porous ceramic pressure plate extractor through a procedure developed by Milks et al. (1989). Unavailable water was determined with four replications per substrate. Data were subjected to ANOVA to compare substrates nested within cooperator sites. Means were separated within a sieve size using Fisher's protected least significance difference test, where $\alpha=0.05$.

Moisture characteristic curves were determined with methods similar to those described by Gabriel et al. (2009). Briefly, columns $(152.4 \mathrm{~cm}$ tall $\times 7.6 \mathrm{~cm}$ i.d. $)$ were cut from schedule 40 polyvinyl chloride rigid pipe and were hand-packed with each substrate. After filling, columns were attached to a rubber coupling $(8.6 \mathrm{~cm}$ i.d.) and fastened with hose clamps (Fernco, Inc., Davison, MI). Columns were bottom-saturated with water for $4 \mathrm{~h}$ or greater, then remained saturated for $8 \mathrm{~h}$ or greater, and allowed to drain to $\approx 6 \mathrm{~cm}$ above the base of the column $\left(\mathrm{Z}_{0}\right)$ for $4 \mathrm{~h}$ or longer. Columns were placed in a freezer at $-21{ }^{\circ} \mathrm{C}$ for $2 \mathrm{~d}$ or greater. Frozen cores were cut into 16 sections. Actual height of cut sections was determined by measuring height at four points along the circumference with a digital caliper (Model
CD-6 CS; Mitutoyo, Kanagawa, Japan); volume was calculated for each section separately using its averaged height. The midpoint of each section was used to calculate the midpoint height of each column above $Z_{0}$, which would represent the tension $\left(\mathrm{cm} \mathrm{H}_{2} \mathrm{O}\right)$ in each section. Each cut section was weighed, ovendried at $60{ }^{\circ} \mathrm{C}$ for $3 \mathrm{~d}$, and weighed again to determine water content $\left(\mathrm{cm}^{3} \cdot \mathrm{cm}^{-3}\right)$. Moisture characteristic curves were plotted as scatterplots of tension (column height, $\mathrm{cm}$ ) vs. water content. From MCC, easily available water (EAW) was calculated as the percent of available water between 10 and $50 \mathrm{~cm}$ suction $\left(\mathrm{H}_{2} \mathrm{O}\right)\left(\mathrm{EAW}=\theta_{50}-\theta_{10}\right)$, whereas waterbuffering capacity $\left(\theta_{100}-\theta_{50}\right)$ was calculated as percent water available between 50 and $100 \mathrm{~cm}$ suction (de Boodt and Verdonck, 1972). There were three columns per substrate type. Data for each substrate type within each cooperator site were fit to log-logistic curves described by Altland et al. (2010). Curves for substrates were compared with other substrates within a site using the lack-of-fit test.

\section{Results and Discussion}

Multivariate ANOVA indicated each of the $\mathrm{PB}$ and wood base materials differed in PSD $(P=0.0001$; Table 2$)$. Univariate ANOVA within sieve size revealed significant differences among materials at each sieve size. Drzal et al. (1999) and Puustjarvi and Robertson (1975) separated soilless substrates into three classes; coarse [greater than $2.0 \mathrm{~mm}(0.08 \mathrm{in})]$, medium [0.5 to $2.0 \mathrm{~mm}$ (0.02 to $0.08 \mathrm{in})$ ], and fine [less than $0.5 \mathrm{~mm}$ (0.02 in)]. According to this convention, $\mathrm{PW}$ had a greater percentage of fines than $\mathrm{PB}$ from Site 2 but less than PB from Sites 1, 3, and 4. Pine wood had similar percentage of medium particles to $\mathrm{PB}$ from Site 4 but more from Sites 1 through 3. Pine wood had more coarse particles than PB from site 4 but similar or fewer coarse particles than all other PB sources. In general, PW used in this study had particle size distribution that would fall within the general coarseness of the PB sources used by the four sites. By this convention for classifying fine, medium, and coarse particles, Jackson et al. (2010) reported a pine tree substrate composed of the aboveground portions of delimbed trees to have $5.7 \%, 30.8 \%$, and $63.5 \%$ fine, medium, and coarse particles, respectively, after passing through a hammermill with a $1.6-\mathrm{cm}$ screen (Meadow Mills Inc., North Wilkesboro, NC). Similarly, Fain et al. (2008) reported a Wholetree substrate comprised of all shoot portions of Loblolly pine (P. taeda) passed through a 1-cm screen (Model 30 Hammermill; C.S. Bell Co., Tiffin, $\mathrm{OH}$ ) had $2.5 \%, 31.8 \%$, and $65.7 \%$ fine, medium, and coarse particles, respectively. The substrates described by Fain et al. and Jackson et al. had similar fine particles but fewer medium and more coarse particles than that used in this study. This is surprising considering the screen sizes used by these other two authors were much smaller than that used in our research $(1.6$ or $1 \mathrm{~cm}$ vs. 7.5 and $5 \mathrm{~cm}$ ). The discrepancy may be the result of the relatively smaller research-scale hammermill used by Fain et al. (2008) and Jackson et al. (2010) compared with the industrial-scale hammermill used in this study. Larger industrial-scale hammermills may further pulverize particles as a result of the greater mill chamber size and velocity of the spinning hammers compared with smaller research-scale hammermills. Caution should be used when predicting particle size of a substrate based solely on screen size of a hammermill.

Because each cooperator site uses a different standard substrate (Table 1), direct comparison of substrates across sites offers little insight into the effects of PW substitution. Instead, PW substitution was analyzed as a nested factor within cooperator site and found to cause significant differences

Table 2. Particle size distribution of pine wood generated by passing chipped whole pine trees (excluding branches) through a hammermill equipped with a 7.5-cm screen and then again with a 5.0-cm screen and pine bark used as the base for substrate blends at four nursery sites.

\begin{tabular}{|c|c|c|c|c|c|c|}
\hline \multirow[b]{2}{*}{ Sieve (mm) } & \multirow[b]{2}{*}{ Pine wood } & \multicolumn{4}{|c|}{ Pine bark ${ }^{z}$} & \multirow[b]{2}{*}{$\operatorname{LSD}_{0.05}$} \\
\hline & & Site 1 & Site 2 & Site 3 & $\overline{\text { Site } 4}$ & \\
\hline Pan & 0.2 & 1.3 & 0.1 & 1.8 & 0.9 & 0.1 \\
\hline 0.11 & 0.3 & 1.8 & 0.2 & 2.6 & 1.5 & 0.1 \\
\hline 0.18 & 0.3 & 1.6 & 0.1 & 2.6 & 1.6 & 0.2 \\
\hline 0.25 & 0.7 & 2.2 & 0.3 & 3.6 & 2.7 & 0.3 \\
\hline 0.35 & 1.3 & 2.7 & 0.6 & 3.8 & 3.5 & 0.4 \\
\hline 0.50 & 3.1 & 4.8 & 1.4 & 5.1 & 6.1 & 0.7 \\
\hline 0.71 & 5.2 & 5.0 & 2.1 & 5.2 & 6.8 & 0.7 \\
\hline 1.00 & 7.7 & 5.6 & 3.6 & 5.3 & 7.8 & 0.9 \\
\hline 1.40 & 13.5 & 8.2 & 7.3 & 7.6 & 10.9 & 1.1 \\
\hline 2.00 & 14.6 & 8.2 & 9.5 & 8.2 & 11.3 & 0.9 \\
\hline 2.80 & 16.1 & 11.1 & 13.7 & 12.4 & 13.7 & 1.3 \\
\hline 4.00 & 19.8 & 16.6 & 18.7 & 20.5 & 16.9 & 2.5 \\
\hline 6.30 & 15.2 & 23.8 & 28.5 & 20.9 & 15.5 & 3.7 \\
\hline 12.50 & 2.1 & 7.1 & 13.9 & 0.3 & 0.7 & 2.6 \\
\hline \multicolumn{7}{|l|}{ Classification } \\
\hline Fine & 2.7 & 9.7 & 1.2 & 14.5 & 10.2 & 1.0 \\
\hline Medium & 44.1 & 31.7 & 24.0 & 31.4 & 42.9 & 3.7 \\
\hline Coarse & 53.2 & 58.6 & 74.8 & 54.1 & 46.9 & 4.4 \\
\hline
\end{tabular}

${ }^{\mathrm{z}}$ Each pine bark source was from a unique supplier $(\mathrm{n}=3)$.

LSD $=$ least significant difference. 
in substrate AS, CC, TP $(P<0.0016)$ as well as UAW $(P<0.0001)$. Air space was affected by additions of PW at Sites 1 and 3, where replacement of $\mathrm{PB}$ caused increased AS (Table 3). Site 3 had more fine particles than all other substrates; thus, addition of the relatively coarse PW would have reduced the proportion of fines in the substrate mix and increase the number and size of macropores. Additions of PW did not affect $\mathrm{CC}$ at Sites 1 and 2. Pine wood decreased CC at Site 3 while increasing CC at Site 4. Reduction of $\mathrm{CC}$ at Site 3 with PW additions is likely the result of adding coarser PW. Increase of CC with PW additions at Site 4 was unexpected. The PW material has fewer fine particles and more coarse particles compared with the $\mathrm{PB}$ at Site 4, thus adding increasing amounts of PW presumably should not increase CC of the blended substrate. Suspecting an error, this group of samples was re-measured with porometers a second time but yielded similar results. The PB fraction at Site 4 comprises $65 \%$ of the substrate with $28 \%$ being comprised of sphagnum peatmoss and composted reground plants (including root balls) from previous production seasons. It is possible that as PB was replaced with increasing amounts of PW in this substrate blend, the larger macropores created by coarser PW were filled by finer particles from the sphagnum peatmoss and reground compost. This hypothesis is supported by the fact that AS did not increase with increasing PW substitution at Site 4 as it did at Site 3, suggesting that the larger macropores were filled with finer particles of other substrate components. Data provided by Jackson et al. (2010) show a similar effect in that whole pine trees processed through hammermills with increasing screen sizes had increasingly coarse PSD. With increasingly coarse PSD, the pine

Table 3. Physical properties of substrates from four cooperating nursery sites. ${ }^{\mathrm{z}}$

\begin{tabular}{|c|c|c|c|c|c|c|}
\hline \multirow{2}{*}{$\begin{array}{l}\text { Cooperator } \\
\text { site }^{\mathrm{y}}\end{array}$} & \multirow{2}{*}{$\begin{array}{c}\text { Pine wood } \\
\text { substitution }(\%)^{\mathrm{x}}\end{array}$} & $\begin{array}{c}\text { Air } \\
\text { space }^{w}\end{array}$ & $\begin{array}{l}\text { Container } \\
\text { capacity }\end{array}$ & $\begin{array}{c}\text { Total } \\
\text { porosity }\end{array}$ & $\begin{array}{c}\text { Unavailable } \\
\text { water }\end{array}$ & \multirow{2}{*}{$\begin{array}{c}\begin{array}{c}\text { Bulk } \\
\text { density }\end{array} \\
\left(\mathrm{g} \cdot \mathrm{cm}^{-3}\right)\end{array}$} \\
\hline & & \multicolumn{4}{|c|}{ 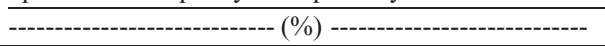 } & \\
\hline \multirow[t]{3}{*}{ Site 1} & Standard & $31.9 \mathrm{c}^{\mathrm{v}}$ & $45.7 \mathrm{NS}$ & $77.6 \mathrm{c}$ & $29.9 \mathrm{a}$ & $0.194 \mathrm{a}$ \\
\hline & 50:50 PW:PB & $40.0 \mathrm{~b}$ & 45.0 & $84.6 \mathrm{~b}$ & $26.4 \mathrm{~b}$ & $0.179 \mathrm{~b}$ \\
\hline & 100:0 PW:PB & $48.7 \mathrm{a}$ & 42.3 & $91.6 \mathrm{a}$ & $24.2 \mathrm{c}$ & $0.161 \mathrm{c}$ \\
\hline \multirow[t]{3}{*}{ Site 2} & Standard & $26.9 \mathrm{NS}$ & $60.6 \mathrm{NS}$ & $87.5 \mathrm{NS}$ & $24.7 \mathrm{NS}$ & $0.178 \mathrm{a}$ \\
\hline & 50:50 PW:PB & 26.3 & 59.1 & 85.4 & 24.2 & $0.157 \mathrm{c}$ \\
\hline & 100:0 PW:PB & 28.8 & 58.9 & 87.7 & 23.7 & $0.167 \mathrm{~b}$ \\
\hline \multirow[t]{3}{*}{ Site 3} & Standard & $16.5 \mathrm{~b}$ & $58.0 \mathrm{a}$ & $74.5 \mathrm{~b}$ & $25.8 \mathrm{a}$ & $0.268 \mathrm{a}$ \\
\hline & 50:50 PW:PB & $34.0 \mathrm{a}$ & $52.3 \mathrm{~b}$ & $86.3 \mathrm{a}$ & $22.5 \mathrm{~b}$ & $0.244 \mathrm{~b}$ \\
\hline & 100:0 PW:PB & $36.1 \mathrm{a}$ & $50.9 \mathrm{~b}$ & $87.0 \mathrm{a}$ & $19.8 \mathrm{~b}$ & $0.238 \mathrm{~b}$ \\
\hline \multirow[t]{3}{*}{ Site 4} & Standard & $21.9 \mathrm{NS}$ & $55.8 \mathrm{c}$ & $77.7 \mathrm{c}$ & $21.4 \mathrm{~b}$ & $0.225 \mathrm{a}$ \\
\hline & 50:50 PW:PB & 20.2 & $63.5 \mathrm{~b}$ & $83.6 \mathrm{~b}$ & $24.4 \mathrm{a}$ & $0.200 \mathrm{c}$ \\
\hline & 100:0 PW:PB & 20.3 & $68.2 \mathrm{a}$ & $88.5 \mathrm{a}$ & $23.8 \mathrm{a}$ & $0.215 \mathrm{~b}$ \\
\hline
\end{tabular}

${ }^{\mathrm{z}}$ At each site, the standard substrate was modified by replacing $0 \%, 50 \%$, or $100 \%$ of the pine bark (PB) fraction with pine wood (PW). Within each site, all components other than pine bark were incorporated at the same level in each substrate ( $n=4$ for unavailable water, $n=3$ for all other parameters).

${ }^{y}$ All sites are located in Ohio. Sites 1,2 , and 4 are commercial nursery producers. Site 3 is an arboretum with extensive production facilities to support internal projects.

${ }^{x}$ Sites 1 through 4 substrates consisted of $100 \%, 67 \%, 60 \%$, and $65 \%$ pine bark, respectively.

${ }^{\mathrm{w}}$ Air space is percent volume of a $7.6 \times 7.6-\mathrm{cm}$ core filled with air after saturation and drainage. Container capacity is percent volume of the same core filled with water after drainage. Total porosity is calculated as the sum of air space and container capacity. Unavailable water is the percent volume of water in a $7.6 \times 2.5-\mathrm{cm}$ core at $1500 \mathrm{kPa}$.

${ }^{\mathrm{v}}$ Means with different letters within a column and cooperator site are significantly different according to Fisher's protected least significant difference test $(\alpha=0.05)$.

NS $=$ nonsignificant difference for a group of means within a column and cooperator site. for a greater percent of the total water content (CC) to be available with increasing PW addition. At Site 3, CC and UAW both decreased with PW additions; thus, there is not likely to be any net change in available water in those substrates. Unavailable water increased slightly at Site 4, although considering the substantial increases in $\mathrm{CC}$ with PW addition, the net result is likely to be increased water availability with PW additions.

Amendment with PW affected moisture characteristic curves (Fig. 1; Table 4). The lack of a fit test found all curves within a site to be different from each other $(P<0.0001$, statistical comparisons not presented). The parameter $\theta_{\mathrm{r}}$ represents the point on the $y$-axis at which the curve flattens to a minimum, which is the decimal percent of water $\left(\mathrm{cm} \cdot \mathrm{cm}^{-1}\right)$ that is retained in substrates at tensions difficult for plants to obtain water (de Boodt and Verdonck, 1972). Only at Site 2 did $\theta_{\mathrm{r}}$ decrease slightly with PW addition (Fig. 1; Table 4). At Sites 1, 3, and 4, $\theta_{\text {r }}$ increased slightly indicating more water retained in substrates over the range of measured tensions and less water available for plant uptake. The parameter $\theta_{\mathrm{s}}$ represents water content when tension is zero (complete saturation) and should be equivalent to $\mathrm{TP}$ (Table 3 ). Comparing $\theta_{\mathrm{s}}$ offers slightly different values than TP measured by porometers (Table 3), although the values are similar and follow the same trend with respect to PW addition within a site. Minor differences between porometer TP and column estimation with $\theta_{\mathrm{s}}$ are likely the result of differences in $\mathrm{D}_{\mathrm{b}}$ from variation in packing procedures. Although $\theta_{\mathrm{s}}$ is a critical part of the MCC, the value does not hold much practical significance because the TP of a substrate is less important than the balance of AS and CC that comprises TP. The parameter $b$ is the tension at which water content declines from the maximum and sometimes referred to as the air entry value. The greater the value of $b$, the more saturated a substrate will be at lower tensions. The parameter $b$ changes very little with PW additions within a site and thus its interpretation has little practical importance. The parameter $x_{0}$ is the tension at which the sigmoid curve changes from convex to concave (inflection point) and is the most important parameter in how it shapes the MCC. As $x_{0}$ increases, the inflection point moves to the right resulting in a higher value of water content at $10 \mathrm{~cm}$ tension. This in turn results in higher calculated values for EAW. The parameter $x_{0}$ decreases with increasing PW substitution in Site 1 substrates, causing a concomitant decrease in EAW. Parameter $x_{0}$ decreases slightly at Site 3 and is relatively constant at Sites 2 and 4 . Changes in $x_{0}$, or lack thereof, are reflected in calculated EAW values. Across the 12 unique substrates evaluated in this study, the parameter $x_{0}$ and EAW are highly correlated $\left(R^{2}=0.9225\right)$. All other fitted parameters are far less correlated to EAW $\left(R^{2}<0.4002\right)$. Easily available water represents the decimal percent volume of 

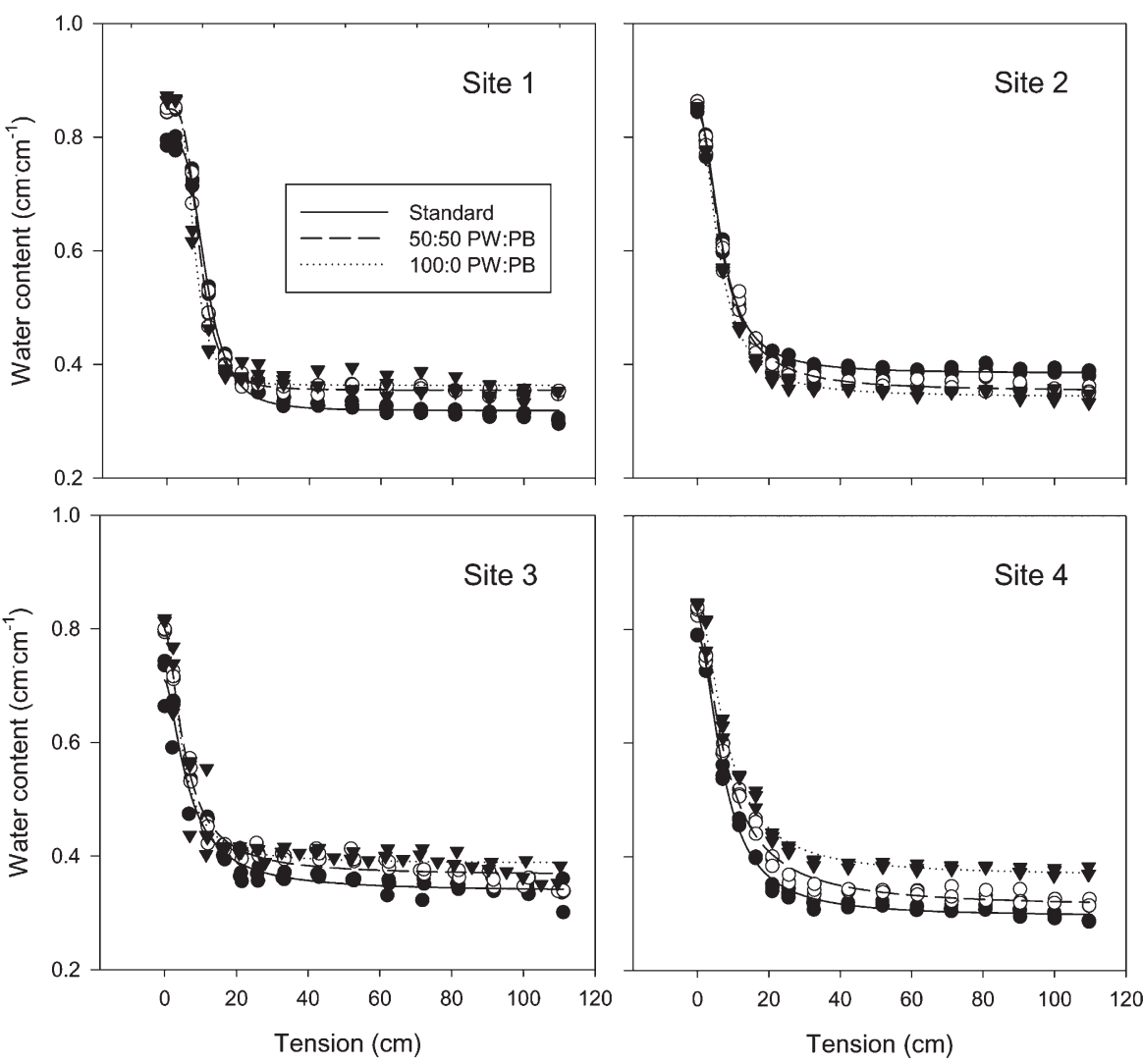

Fig. 1. Moisture characteristic curves for substrate at four different cooperating nursery sites. Within each site, the standard substrate represents the predominantly pine bark substrate used by the nursery. The 50:50 PW:PB represents a substrate in which 50\% of the pine bark fraction is replaced with pine wood and 100:0 PW:PB represents a substrate in which 100\% of the pine bark is replaced with pine wood. Fitted log logistic curves for each substrate are provided in Table 4.

Table 4. Estimated parameters for moisture characteristic curves of nursery substrates from four different cooperating nursery $\operatorname{sites}^{\mathrm{z}}$ (Fig. 1).

\begin{tabular}{|c|c|c|c|c|c|c|c|c|}
\hline \multirow[b]{2}{*}{ Site } & \multirow[b]{2}{*}{ Substrate ${ }^{y}$} & $\theta_{\mathrm{r}}^{\mathrm{x}}$ & $\theta_{\mathrm{s}}$ & \multirow[b]{2}{*}{$\mathrm{b}$} & \multirow[b]{2}{*}{$\mathrm{x}_{0}$} & \multirow[b]{2}{*}{$r^{2}$} & $\mathrm{EAW}^{\mathrm{w}}$ & $\mathrm{WBC}^{\mathrm{v}}$ \\
\hline & & \multicolumn{2}{|c|}{$\overline{---\left(\mathrm{cm}^{3} \cdot \mathrm{cm}^{-3}\right)---}$} & & & & \multicolumn{2}{|c|}{$\overline{-----\left(\mathrm{cm}^{3} \cdot \mathrm{cm}^{-3}\right)-----}$} \\
\hline \multirow[t]{3}{*}{1} & Standard & 0.32 & 0.79 & 3.61 & 10.97 & 0.9954 & 0.28 & 0.002 \\
\hline & 50:50 PW:PB & 0.36 & 0.85 & 3.87 & 9.14 & 0.9962 & 0.20 & 0.001 \\
\hline & 100:0 PW:PB & 0.36 & 0.87 & 3.89 & 7.60 & 0.9896 & 0.13 & 0.000 \\
\hline \multirow[t]{3}{*}{2} & Standard & 0.38 & 0.84 & 2.13 & 6.87 & 0.9962 & 0.13 & 0.005 \\
\hline & 50:50 PW:PB & 0.35 & 0.86 & 1.86 & 6.86 & 0.9930 & 0.15 & 0.009 \\
\hline & 100:0 PW:PB & 0.34 & 0.85 & 1.95 & 6.22 & 0.9978 & 0.13 & 0.006 \\
\hline \multirow[t]{3}{*}{3} & Standard & 0.34 & 0.71 & 1.61 & 6.53 & 0.9658 & 0.11 & 0.009 \\
\hline & 50:50 PW:PB & 0.37 & 0.80 & 1.66 & 5.67 & 0.9831 & 0.11 & 0.008 \\
\hline & 100:0 PW:PB & 0.39 & 0.82 & 1.82 & 4.59 & 0.9482 & 0.08 & 0.004 \\
\hline \multirow[t]{3}{*}{4} & Standard & 0.30 & 0.79 & 1.84 & 7.50 & 0.9957 & 0.17 & 0.010 \\
\hline & 50:50 PW:PB & 0.31 & 0.83 & 1.59 & 8.01 & 0.9927 & 0.19 & 0.017 \\
\hline & 100:0 PW:PB & 0.37 & 0.85 & 1.75 & 8.25 & 0.9929 & 0.18 & 0.014 \\
\hline
\end{tabular}

${ }^{\mathrm{z}}$ Each site provided their standard substrate comprised primarily of pine bark, a substrate with $50 \%$ of the pine bark replaced with pine wood, and a third substrate with all of the pine bark fraction replaced with pine wood $(n=4)$.

${ }^{y}$ Substrates at Sites 1 through 4 consisted of $100 \%, 67 \%, 60 \%$, and $65 \%$ pine bark, respectively.

xParameters were estimated for the log-logistic function $\theta_{\mathrm{r}}+\left(\theta_{\mathrm{s}}-\theta_{\mathrm{r}}\right) /\left[1+\left(\mathrm{h} / \mathrm{x}_{0}\right)^{\mathrm{b}}\right]$, where $\theta_{\mathrm{r}}$ represents residual water content, $\theta_{\mathrm{s}}$ represents water content at saturation, $\mathrm{b}$ (when $\mathrm{n}<\mathrm{x}_{0}$ ) is the air entry value, and $\mathrm{x}_{0}$ is the tension at which the curve changes from convex to concave. The parameter $r^{2}$ is the coefficient of determination for the model.

wEAW represents easily available water, or that which is available between -10 and $-50 \mathrm{~cm}_{2} \mathrm{O}$.

${ }^{v}$ WBC represents water-buffering capacity, or that which is available between -50 and $-100 \mathrm{~cm}_{2} \mathrm{O}$.

a saturated container $\left(\mathrm{cm} \cdot \mathrm{cm}^{-3}\right)$ filled with water that is easily absorbed by plants. The highest EAW occurred in substrates from Site 1, which surprisingly uses $100 \%$ PB and had the lowest measured $\mathrm{CC}$ in this study. These data suggest that PB used at Site 1 holds less total water than other substrates, although more of that water is available for plant uptake. Substitution of PB with PW reduced EAW at Site 1 to levels similar at other sites.

It is difficult to predict how blending of different components will affect physical properties of the mixed substrate. Gabriel et al. (2009) found that predicting the effect on AS, CC, or TP from the mixing of douglas fir bark, peatmoss, and pumice was not possible. If this relatively simple array of materials could not be predicted, then it should not be surprising that interactions among PB, PW, peatmoss, compost, sand, and other minor amendments yield unexpected results. Addition of PW to this particular substrate cannot be explained entirely with the potentially false logic that coarser amendments yield coarser substrates with increased AS and decreased CC.

This research does not suggest that additions of PW results in superior or inferior substrates or that the resulting properties of any of the 12 substrates are more conducive to plant growth. Lowder et al. (2006) grew hellebores (Helleborus $\times$ hybridus and H. foetidus) in PB amended with different rates of sand or peatmoss and demonstrated that hellebores are best grown in substrates with high CC and low AS. Conversely, Breedlove et al. (1999) grew 'Hershey Red' azalea (Rhododendron sp.) in PB alone or PB amended with peatmoss or perlite and showed that greatest growth and quality occurred in $100 \%$ PB, which among all substrates had the highest AS and lowest CC. No single substrate is universally suitable to all plant species (Lea-Cox and Smith, 1997). With respect to physical properties, plants will respond more favorably to substrates that best mimic conditions of their natural habitats in terms of air and water availability. The use of this research is to demonstrate that substitution of $\mathrm{PB}$ with $\mathrm{PW}$ will result in substrates with changed physical properties but properties still within the range necessary for crop growth (Yeager et al., 2007). Unfortunately, it does not seem that any generalizations can be made of how PW additions will affect substrate physical properties of the vast variety of substrate blends used by container nurseries. In some cases, the more coarse nature of the PW used in these studies caused an increase in AS and UAW with a decrease in CC. However, parameters of some substrates did not change. From the standpoint of physical properties alone, growers may need to consider slight changes in their irrigation practices to accommodate changes in water-holding characteristics of the media. That said, PW generated from whole loblolly pine, chipped, and then processed through equipment similar to that used in this study can be used as a viable substitute for $100 \%$ of the $\mathrm{PB}$ in substrates typical of the Ohio nursery industry.

\section{Literature Cited}

Altland, J.E., J.S. Owen, Jr., and W. Fonteno. 2010. Developing moisture characteristic curves and their descriptive functions at low-tensions for soilless substrates. J. Amer. Soc. Hort. Sci. 135: 563-567.

Boyer, C.R., G.B. Fain, C.H. Gilliam, T.V. Gallagher, H.A. Torbert, and J.L. Sibley. 2008. Clean chip residual as a substrate for perennial nursery 
crop production. J. Environ. Hort. 26:239246.

Breedlove, D., L. Ivy, and T. Bilderback. 1999. Comparing potting substrates for growing 'Hershey Red' azaleas. Proc. Southern Nurs. Assoc. Res. Conf. 44:71-75.

de Boodt, M. and O. Verdonck. 1972. The physical properties of the substrates in horticulture. Acta Hort. 26:37-44.

Drzal, M.S., W.C. Fonteno, and D.K. Cassel. 1999. Pore fraction analysis: A new tool for substrate testing. Acta Hort. 481:43-54.

Fain, G.B., C.H. Gilliam, J.L. Sibley, and C.R. Boyer. 2008. WholeTree substrates derived from three species of pine in production of annual vinca. HortTechnology 18:13-17.

Fonteno, W.C. and T.E. Bilderback. 1993. Impact of hydrogel on physical properties of coarsestructured horticultural substrates. J. Amer. Soc. Hort. Sci. 118:217-222.

Gabriel, M., J.E. Altland, and J. Owen. 2009. The effect of peat moss and pumice on the physical and hydraulic properties of douglas-fir bark based soilless substrate. HortScience 44:874878.

Jackson, B.E., R.D. Wright, and M.C. Barnes. 2010. Methods of constructing a pine tree substrate from various wood particle sizes, organic amendments, and sand for desired physical properties and plant growth. Hort Science 45:103-112.

Lea-Cox, J.D. and I.E. Smith. 1997. The interaction of air-filled porosity and irrigation regime on the growth of three woody perennial (citrus) species in pine bark substrates. Proc. Southern Nurs. Assoc. Res. Conf. 42:169-174.

Lowder, A.W., H.T. Kraus, S.L. Warren, and A. Prehn. 2006. Nursery production of Helleborus sp.: Substrate irrigation. Proc. Southern Nurs. Assoc. Res. Conf. 51:36-39.

Lu, W., J.L. Sibley, C.H. Gilliam, J.S. Bannon, and Y. Zhang. 2006. Estimation of U.S. bark generation and implications for horticultural industries. J. Environ. Hort. 24:29-34.
Milks, R.R., W.C. Fonteno, and R.A. Larson. 1989. Hydrology of horticultural substrates: I. Mathematical models for moisture characteristics of horticultural container media. J. Amer. Soc. Hort. Sci. 114:48-52.

Pokorny, F.A., P.G. Gibson, and M.G. Dunavent 1986. Prediction of bulk density of pine bark and/or sand potting media from laboratory analyses of individual components. J. Amer. Soc. Hort. Sci. 111:8-11.

Puustjarvi, V. and R.A. Robertson. 1975. Physical and chemical properties, p. 23-38. In: Robinson, D.W. and J.G.D. Lamb (eds.). Peat in horticulture. Academic Press, London, UK.

Wright, R.D. and J.F. Browder. 2005. Chipped pine logs: A potential substrate for greenhouse and nursery crops. HortScience 40:1513-1515.

Yeager, T.H., C.H. Gilliam, T.E. Bilderback, D.C. Fare, A.X. Niemiera, and K.M. Tilt. 2007. Best management practices: Guide for producing nursery crops. Southern Nursery Assoc., Atlanta, GA. 